\title{
BMJ Open Identifying ethical values for guiding triage decisions during the COVID-19 pandemic: an Italian ethical committee perspective using Delphi methodology
}

\author{
Anita Zeneli, ${ }^{1}$ Giovanni Brandi, ${ }^{2}$ Giuseppe Di Pasquale, ${ }^{3}$ Danilo Orlandini, ${ }^{3}$ \\ Piero De Carolis, ${ }^{3}$ Francesca Bravi (D) , ${ }^{4}$ Francesco Pugliese, ${ }^{5}$ Elisabetta Poluzzi, ${ }^{2}$ \\ Fausto Catena, ${ }^{6}$ Filippo Giovanardi, ${ }^{7}$ Giorgia Valpiani, ${ }^{4}$ Renato Mantovani, ${ }^{3}$ \\ Eugenia Magnanimi, ${ }^{5}$ Primiano lannone ${ }^{8}$
}

To cite: Zeneli A, Brandi G, Di Pasquale G, et al. Identifying ethical values for guiding triage decisions during the COVID-19 pandemic: an Italian ethical committee perspective using Delphi methodology. BMJ Open 2021;11:e043239. doi:10.1136/ bmjopen-2020-043239

- Prepublication history and additional supplemental material for this paper are available online. To view these files, please visit the journal online (http://dx.doi.org/10.1136/ bmjopen-2020-043239).

Received 03 August 2020 Revised 04 February 2021 Accepted 10 March 2021

Check for updates

(c) Author(s) (or their employer(s)) 2021. Re-use permitted under CC BY-NC. No commercial re-use. See rights and permissions. Published by BMJ.

For numbered affiliations see end of article.

Correspondence to

Dr Francesca Bravi;

francesca.bravi@auslromagna.it

\section{ABSTRACT}

Objectives This study aimed to identify the guiding ethical principles that should be considered for critical resource allocation during pandemic emergency situations, and especially for the COVID-19 outbreak. The secondary objective was to define the priority to be assigned to each principle.

Setting The study was conducted from March to June 2020 within the context of an ethical committee (EC) in Northern Italy.

Participants Eleven EC members and five additional external healthcare and bioethical professionals, forming a multidisciplinary panel, took part in the study.

Primary and secondary outcome measures The compilation of a list of ethical principles (maximum of 10 items) and their priority ranking and application within an emergency pandemic context was established as the expected outcome of this work.

Results A consensus on 10 guiding ethical principles was reached by the multidisciplinary panel. Transparency ranked first on the priority list as the most frequently voted principle, followed by the number of lives saved, life-years saved, respect for individuals' autonomy and equity. Other principles including life cycle, 'sickest first', reciprocity, instrumental value and lottery were also considered appropriate as potential tiebreakers. These principles were discussed and made consistent with the current Italian pandemic context by producing an explanatory document. Conclusions The identified principles could be used in preparedness plans to guide resource allocation during pandemic events. By combining their rank and relevance in relation to disease, health system organisations, social and economic settings, and critical resources at risk of scarcity, these principles could help to maximise the benefit of resource use for the community, thus reducing inequalities for individuals.

\section{INTRODUCTION}

Given the challenges that it poses, the COVID-19 pandemic has been the most important global health emergency of the past few decades, especially for the public

\section{Strengths and limitations of this study}

- The use of a combined snowball and Medical Subject Headings-based search for relevant documents permitted an exhaustive assessment of most, if not all, of the ethical principles at stake.

- The multidisciplinary profile of the panel guaranteed a wider ethical and content input to the discussion.

- The adoption of a modified ethical Delphi technique with a three-round voting method and Rawls' principles permitted a balanced assessment of the pros and cons of each scrutinised principle and an unbiased consensus.

- The absence of health policymakers, citizens and patients in the panel may have negatively affected the trustworthiness of the selected principles and of their ranking.

- The lack of validation and field testing of the selected principles by other ethical committees and healthcare organisations calls for caution when using them.

healthcare systems in the countries most affected by the spread of the virus. ${ }^{12}$ The potential of SARS-CoV-2 to evolve towards an acute respiratory distress has put an extraordinary and sustained demand on public healthcare systems by exceeding their capacity to respond, thus making the rationing of indivisible scarce healthcare resources ${ }^{3}$ unavoidable. While prioritising such limited resources for patients is already important under normal circumstances, it becomes vital during pandemic events such as the COVID-19 outbreak $^{45}$ to confer the largest health benefit to communities. However, although several triage tools are available to address these problems, their use during the current infectious outbreak has proven problematic in the USA. ${ }^{6}$ In fact, the bioethical debate on which values should be used to guide allocation 
decisions during pandemics (including COVID-19) has been ongoing for decades. Furthermore, the question as to whether allocation should be informed by age criteria alone $^{7}$ (with the hotly debate around ageism), by one of several ethical approaches available (ie, utilitarianism, prioritarianism, equalitarianism, personalism), by more empirical solutions (lottery, first-come-first served) ${ }^{8}$ or by some combination thereof varies across cultures, healthcare systems and socioeconomic models. However, the COVID-19 pandemic has also resulted in a health and humanitarian crisis in Italy, with dramatic consequences ${ }^{9}$ and a toll of nearly 85000 deaths. ${ }^{10}$ The northern regions have been the most severely hit by the pandemic, leading to great imbalance between the availability of intensive care units (ICUs) and the number of patients in need of critical care, and creating a heavy burden on attending physicians and intensive care nurses and unprecedented stress on the healthcare system. While an embedded triage system for the evaluation of such cases was not available at either national/regional level or in single hospitals, the Italian Society of Anesthesia, Analgesia, Resuscitation and Intensive Care (SIAARTI) produced some broad criteria with an ad hoc position statement grounded on a 'soft' utilitarian basis. ${ }^{511}$ Age was therein considered as a possible, although extreme, reason for exclusion from access to ventilators. The Italian National Bioethical Council (NBC) produced a COVID-19 statement on this issue more than 1 month later and although the document contained conflicting opinions, it advocated personalisation of care and clinical appropriateness as the main principles to be adopted. ${ }^{12}$ Recently, a joint effort by SIAARTI and Società Italiana Medicina Legale e delle Assicurazioni, under the auspices of Istituto Superiore di Sanità, produced a consensus paper on the issue that was uploaded onto the website of the National Clinical Guidelines Clearinghouse (Sistema Nazionale Linee Guida-SNLG) ${ }^{13}$ in January 2021. This document mitigates the earlier position on age limits but does not represent a triage tool or algorithm. On another note, the decision to allocate ICU beds in 2020 was made without any nationally endorsed or publicly accepted triage tool, depending mainly on the subjective and variable judgement of overwhelmed physicians and local availability of respirators and intensive care personnel. This fuelled unacceptable inequalities in access to care and in rates of avoidable deaths across Italian regions, despite the grounding principles of equity, fairness and universal right to healthcare laid down by National Law No. 833 of 1978 that heralded the establishment of the Italian National Health Service (NHS).$^{14}$ For the same reasons, COVID-19-related policies on health interventions that were, at times, critically insufficient to achieve optimal clinical outcomes (diagnostic tests, case tracing and management, protection of vulnerable people in the primary care setting and residential homes, use of personal protective equipment (PPE) and innovative therapies), differed from one Italian region to another, associated with substantial differences of mortality rates across Italian regions with a similar community circulation of the virus. ${ }^{15}{ }^{16}$ Lastly, vaccine allocation to people most in need of it is currently being determined without any publicly discussed and nationally endorsed ethical framework.

Italian ethical committees (ECs) are independent, no profit bodies operating within a defined local public health or research authority and coordinated by the Italian Medicines Agency (Agenzia Italiana del FarmacoAIFA). They are legally established mainly to protect individuals taking part in biomedical research by giving a binding response to AIFA and local health authorities to accept, modify or reject any request for an observational or experimental study involving human subjects (or their biological identifiable tissues and samples) and to approve (or not) the compassionate use of drugs in individual cases. However, they are rarely involved, from a legal point of view, in giving their binding advice on ethical issues arising from clinical practice. ${ }^{17}$ With such a wide array of ethical dilemmas and unanswered questions raised by COVID-19, no EC in Italy was asked to discuss, nor were any forthcoming in offering a point of view of their own, with one exception. ${ }^{18}$ On the contrary, ECs should be an active part of these efforts according to renowned bioethical forums. ${ }^{19}$ Given our concern about the ethical gaps and about how COVID-19 pandemic was being managed in our country, we discussed the issue in depth and felt the need to identify ethical allocation principles to address broad triage questions raised by regional health authorities, hospitals and emergency medical services regarding the evaluation of individual cases when needs exceed the available resources (even after all the contingency plans have been correctly set up). We also aimed to compile a priority list of guiding ethical principles contextualised to the Italian health system and the most common scenarios of decision-making.

\section{METHODS}

Our EC, one of the largest ethical bodies in Italy, ${ }^{20}$ is located in the region of Emilia-Romagna, an area severely affected by the COVID-19 pandemic. The EC operates independently within the infrastructure of two large university hospitals (Universities of Bologna and Ferrara), two nationally renowned research centres, and the public hospitals of Bologna, Ferrara and Imola, covering an overall catchment area of 1344000 people. The study proposal was discussed and approved during the monthly meeting of our EC on 19 March 2020, followed by a dedicated web-based conference where all EC members were invited to participate. After discussing the general and ethical concerns of COVID-19 in Italy, 11 of the $40 \mathrm{EC}$ members manifested an interest in the topic and agreed to take part in the study. In order to achieve a multidisciplinary and multiprofessional working group profile, a purposeful sampling approach was used to appoint the five external components (PF, VG, ME, FP and FV) needed to complete the required expertise. The panel was 
thus composed of critical care physicians involved in the SARS-CoV-2 pandemic, nurses, lawyers, clinical research experts and bioethicists. All panellists shared an interest in the issue and had long-standing experience in the area of bioethics. The scope of the project was defined by the Steering Committee (AZ, GDP, DO, PDC, PI), presented to the working group in a kick-off meeting. It was decided to address two main questions by the EC perspective:

1. What guiding ethical principles should be considered for critical resource allocation during pandemic emergency situations and especially for the COVID-19 outbreak?

2. What priority should be assigned to each principle?

\section{Justification of the methods}

In order to offer a comprehensive view of the ethical principles and triage models suitable for the pandemic discussion, a review of the literature was carried out using a snowball approach, ${ }^{21}$ starting from the seminal paper of Emanuel et al. ${ }^{4}$ This search was cross-matched for relevance and consistency (by AZ and PI, with any discrepancy resolved by consensus) with a parallel search on PubMed with free text and Medical Subject Headings terms (online supplemental file S1). In this way, 17 triage tools, 2 policy documents, 9 guidelines and 49 documents focusing on general ethical principles were identified and made accessible to the panellists.

There is still an open debate and a lack of consensus in the literature about which values should be used as guiding principles for resource-allocation decisions. Given that the latter would be involved in a decision-making process that could affect many lives, we chose a modified ethical Delphi technique ${ }^{22} 23$ to obtain an impartial and rational voting system and to elicit a balanced consensus on the issues. Experts gave their opinion via email in a threeround voting system. To allow for in-depth reflection of the wide-ranging perspectives on the issue, a summary of the anonymised textual contributions of experts was sent to panel members after each voting round, thus reducing the risk of being influenced by dominant members of the panel. We describe the Delphi methodology as modified because video-conference meetings followed each voting round to present and discuss results and reinforce the controlled feedback between experts and the Steering Committee. The participants were not persuaded to vote for specific principles, indeed they were asked to vote impartially and rationally with an experimental thought approach like one Rawls described as the 'original position' in his theory for justice. ${ }^{24}$

A mixed-methods approach was used to identify the ethical principles. Based on the paper by Emanuel et $a l$ and three other documents deemed as most relevant, ${ }^{425-27}$ the Steering Committee identified the baseline 'candidate' set of ethical principles. Additional ethical principles were identified by the experts after independent reading of the literature documents and submitted (with accompanying notes and references) to the Steering Committee. ${ }^{88-32}$ A list of putative principles was then built and voted on via email by the experts. After the first-round voting, an anonymised summary was sent to panel members containing both the voting results and the comments of all the experts for each principle. The Steering Committee provided controlled feedback and textual analysis of expert contributions to identify controversial views requiring discussion and clarification during the following web-based meeting. Splitting or merging of some of the voted principles after bioethical expert input was considered during this step for consistency with acknowledged bioethical domains, and the final list of the 10 most voted principles was obtained. The priority ranking of each ethical principle of the final list was defined in the second-round voting via email, with scores ranging from 1 (lowest priority) to 4 (highest priority). One last web meeting was held where the final consensus on the list of principles and their ranking and contextualisation was discussed. Figure 1 shows the key methodological steps of the ethical Delphi used in this work.

\section{Patient and public involvement}

No patient involved.

\section{Data analysis}

A mixed-methods approach was used for data analysis. No K-statistics were used to measure the agreement among experts or to select the principles of the final list. Conversely, an unweighted voting procedure and a simple descriptive analysis were used in both stages to present voting results and scores (rates of concordance, means and SD). A qualitative approach was used to analyse the textual contributions of the participants.

\section{RESULTS}

In addition to the seven initial 'baseline' principles (table 1, bold font) derived from the aforementioned seminal paper, ${ }^{4}$ a further 18 ethical principles were identified by the experts.

The Steering Committee listed the ethical principles on the basis of the quantitative voting and the text contributions of the experts. The quantitative voting results of the ethical principles evaluated by the panel are shown in table 1 as proportions of agreement, disagreement and abstentions for each voted principle. At the first-round Delphi session, no single principle was deemed sufficient to be a standalone criterion to guide the ethical triage of scarce resources. Transparency, Numbers of lives saved, Life-years saved and Equity were considered as leading values. The analysis of textual contributions of experts resulted in accepting some other principles which, after plenary discussion, were considered as contributing to the same ethical domain and thus merged together. This was the case for: procedural justice and accountability (merged into transparency); dignity, informed consent, anticipated willingness of care and beneficence/nonmaleficence (merged into respect for persons and their autonomy). Youngest first was merged into the 'life cycle' 
Fig. 1

Main Question: What ethical principles are needed in decision-making for the allocation of critical resources during a public emergency caused by a pandemic Ethical DELPHI with mixed methods approach

\section{Recruitment of Expert Panel}

- Project Introduction

- Online platform presentation

- Objectives and methods

- Intruments/worksheets instructions
Planning:

- Steering Committee (AZ, PI, PDC, GDP, DO)

- Project design, objectives, methods, worksheets for data collecting and agreement rating

- Literature review (snowballing \& systematic review)

- Creation of online platform with selected papers

- Questions for each phase

- Cutoff for agreement intensity to define the panel consensus

\section{First round voting}

Aim: to identify ethical principles

Experts independently:

- Consulted the uploaded papers:

- Identified principles;

Distribution of questions and

data collection worksheets

- Evaluated whether or not to include the principle in decision-making for resource allocation during pandemics

- Motivated their choices

\section{Feedback and controlled}

feedback

\section{Second round voting}

Aim: To prioritize ethical principles and evaluate

the document proposal

Experts independently:

- First-round result presentation;

- Distribution of questions and data

- Ranked principles collection worksheets

- Textual analysis from the first round, highlighting critical issues/hidden disagreements needing to be discussed

- Second-round data collection

\section{Consensus meeting (third round)}

Aim: to evaluate and approve the consensus document

Experts:

- Proposal of the consensus document;

- Discussion

- Approval of the final consensus document
- Presentation of second-round results and proposal of explanatory document

- Preparation of final approved consensus document

Figure 1 Key steps of ethical Delphi for resource-allocation decision-making during pandemics.

principle. Sickest first, reciprocity, instrumental value and lottery entered unmerged into the final 10 items list. The remaining criteria were not considered ethically relevant or valid per se or amenable to be included in any ethical domain. Figure 2 shows how the ethical principles of the initial list were processed during the first-round and 
Table 1 First-round and second-round Delphi voting results

\section{First-round voting}

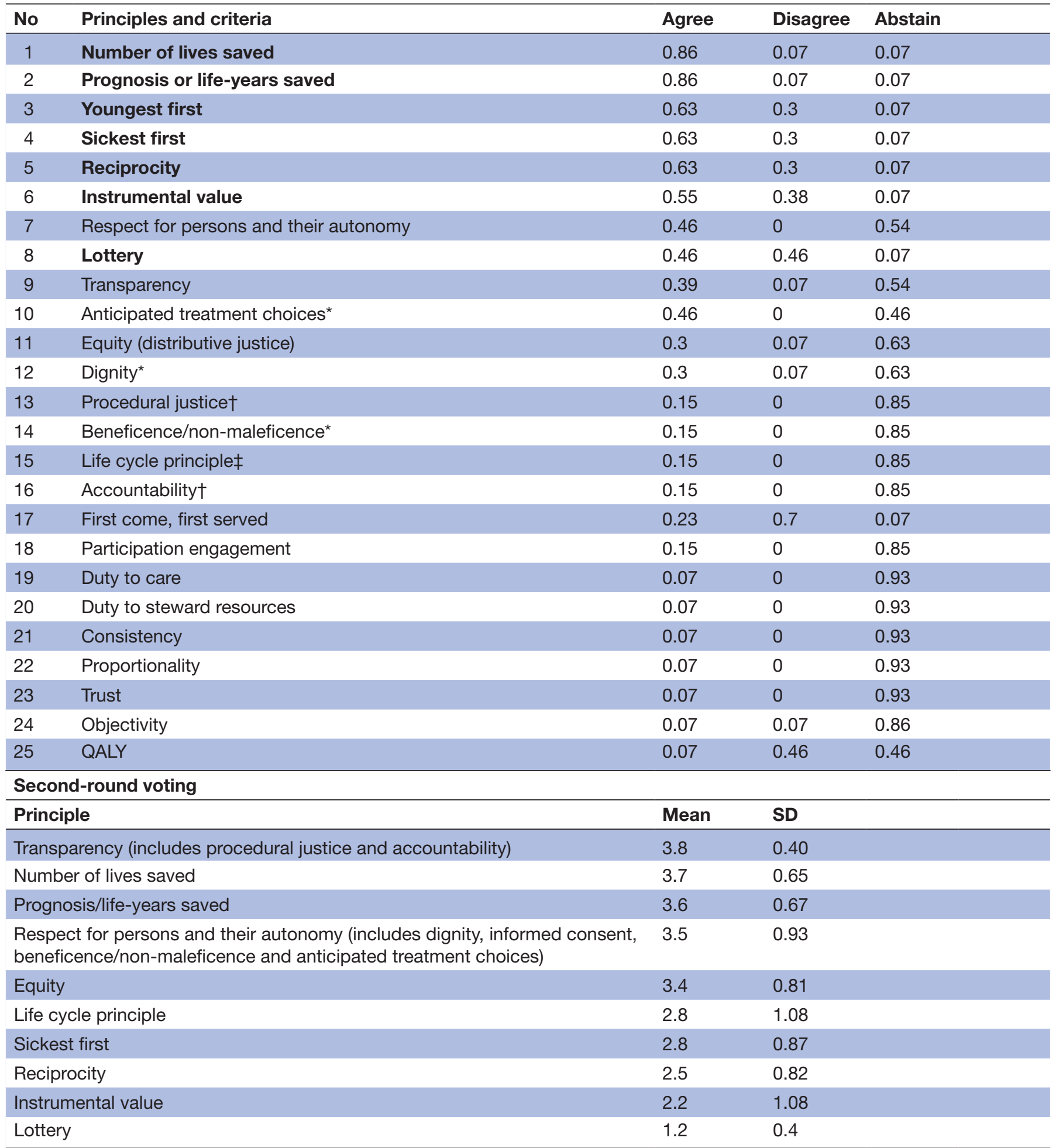

*After first Delphi round, included in Respect for persons and their autonomy.

†After first Delphi round, included in Transparency.

$\ddagger$ After first Delphi round, included in Youngest first.

QALY, quality-adjusted life-year.

second-round voting. The priority ranking (mean scores and SDs) of the 10 leading principles (second-round voting) is presented in the lower section of table 1 . The identified principles were then discussed, including the context variables relating to the NHS, law enforcement, type of resource considered, Italian perceived societal 
Fig. 2

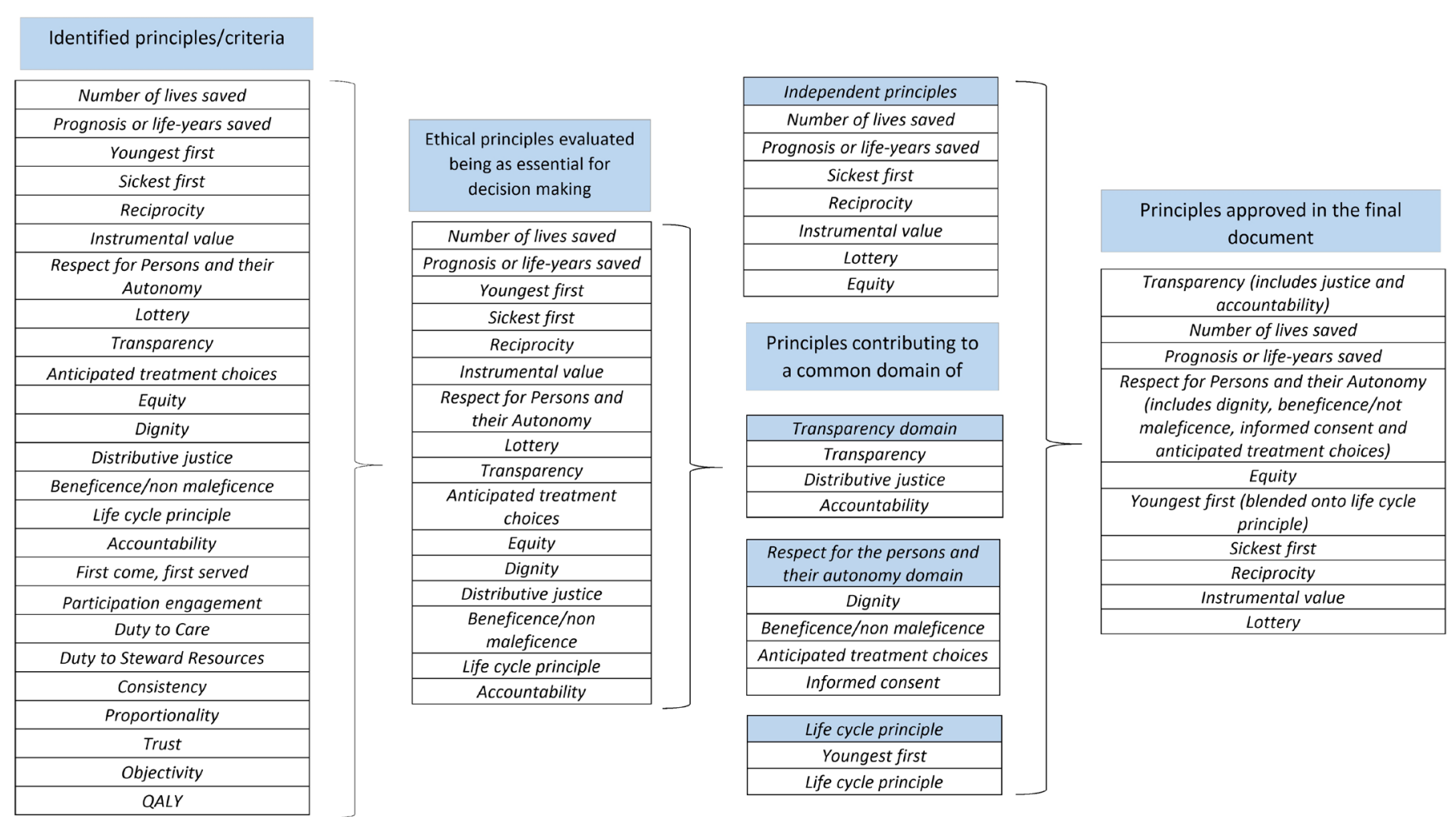

Figure 2 Ethical principles processing. QALY, quality-adjusted life-year.

ethical values and different combined value options (online supplemental file $\mathrm{S} 1$ ).

\section{DISCUSSION}

Up to now, ECs in Italy have mainly been concerned with safeguarding individual cases and patients taking part in biomedical research. The current pandemic has caused an unprecedented impact in our country and elsewhere in terms of the delay in pinpointing essential ethical issues related to the fair allocation of scarce critical resources. As an EC in a region hit hard by COVID-19, we felt a responsibility to try to bridge such a gap by addressing ethical issues raised by the pandemic emergency ${ }^{19} 33$ in a way that is consistent with what has been advocated as the legitimate role of ECs.

An accurate literature search provided sufficient grounds for a thorough discussion about the possible ethical principles to adopt. The modified Delphi technique used for this project helped to minimise distortions of the discussion caused by anchoring and dominant views of the most influential experts of the panel. Furthermore, the multidisciplinarity of the group ensured a wide perspective of thought, facilitating an in-depth evaluation of potential clinical, ethical, social and legal consequences deriving from the application of the individual principles in practice during pandemics, which helped to contextualise them. The results were a culmination of a critical evaluation of the current literature in the field; knowledge of the regulatory context for the exercise of the medical and health professions; values legitimated ${ }^{34} 35$ by our society and experts' own values.

We considered no single principle sufficient per se to satisfy a fair allocation policy and none was considered devoid of potential pitfalls or biases. Rather, a multiprinciple ethical allocation strategy was viewed as appropriate, in agreement with the majority of bioethical experts, to reach a reasonable balance of competing needs and values. $^{4} 8$ 25-32

In our work, transparency was identified as the overarching value and included key ethical dimensions such as procedural justice, clarity and accountability for the steps followed to plan, guide and assess triage deployment, and to justify its legal infrastructure and organisation at a regional or national level. ${ }^{36}$ This value is also emphasised in other European guidelines. ${ }^{28} 3738$

Maximising the number of saved lives had the second highest score, in accordance with most, if not all, pandemic ethical consensus and triage tools. ${ }^{425-3239-41}$ This value also appears to have a wide public consensus. ${ }^{37} 42$ In our opinion, balancing this value with the remaining principles makes triage choices more reasonable and equitable for all, including the vulnerable and disadvantaged who could be harmed by a strict utilitarian approach. Prognosis (or years of life saved) ranked third. The panel discussed at length whether or not to accept long-term prognosis (life-years saved) together with short-term prognosis, 
ultimately accepting the criterion. Other authors have used the term long-term prognosis as an equivalent of life-years saved. This criterion is based on the evaluation of comorbidities and frailty and helps to maximise the number of life-years saved because it gives priority to individuals with longer life expectancy. ${ }^{41}$ The panel also highly valued a careful, personalised and focused assessment of individual patients in agreement with the NBC document ${ }^{12}$ stating that reconciling the individual duty to care of standard clinical practice with ethical problems arising from a community perspective can and must be done. $^{4344}$

Equity, which is among the grounding principles of the Italian ${ }^{34}$ public health system, again with a strong commitment to the adoption of clear-cut criteria at hospital triage level and to the appropriate planning at regional or national basis. However, equity also requires the appropriate planning of the organisational triage infrastructure on a regional or national basis, allowing the equitable distribution of the scarcest resources across patients with similar conditions but in different health organisations and regions. ${ }^{26} 2745$

The panel held an in-depth discussion on the proportionality of care that may lead to an unequal amount of care favouring the most disadvantaged. In fact, it is well known that some ethnic and social minorities and marginal people are paying a disproportionate toll during the present health emergency. ${ }^{46}$ We excluded age as being discriminatory and an unreliable proxy indicator of health status and life expectancy. ${ }^{47} 48$ In contrast, the life cycle principle was accepted by our group as a principle of justice, giving everyone the same chances to live the cycles of a normal life, ${ }^{77-49}$ and we adopted this as a potential tiebreaker. We also discussed the fact that giving the highest priority to adolescents and young adults meets the intuitive perception that the death of an infant is a tragedy, but the death of an adolescent is an even bigger tragedy. ${ }^{8}$ We regarded lifestyle and unsafe health-related practices as not morally relevant to modify this principle in individuals, although we acknowledge that this is not universally accepted. ${ }^{750}$ Adopting the sickest first principle within the context of critical resource allocation during pandemics may not lead to improved outcomes at the population level as survival probability may be very low for the worst-off. However, it was accepted as another possible tiebreaker. Indeed, such a principle, if applied to resource allocation aimed at preventing severe disease (figure 3), can contribute to a public health benefit by reducing the demand for critical resources and the pressure to hospitalise severely ill patients (eg, screening fragile populations through risk stratification, vaccines, PPE, isolation, early treatments).

We ranked reciprocity and instrumental value well below the other principles but accepted them, acknowledging

Fig. 3

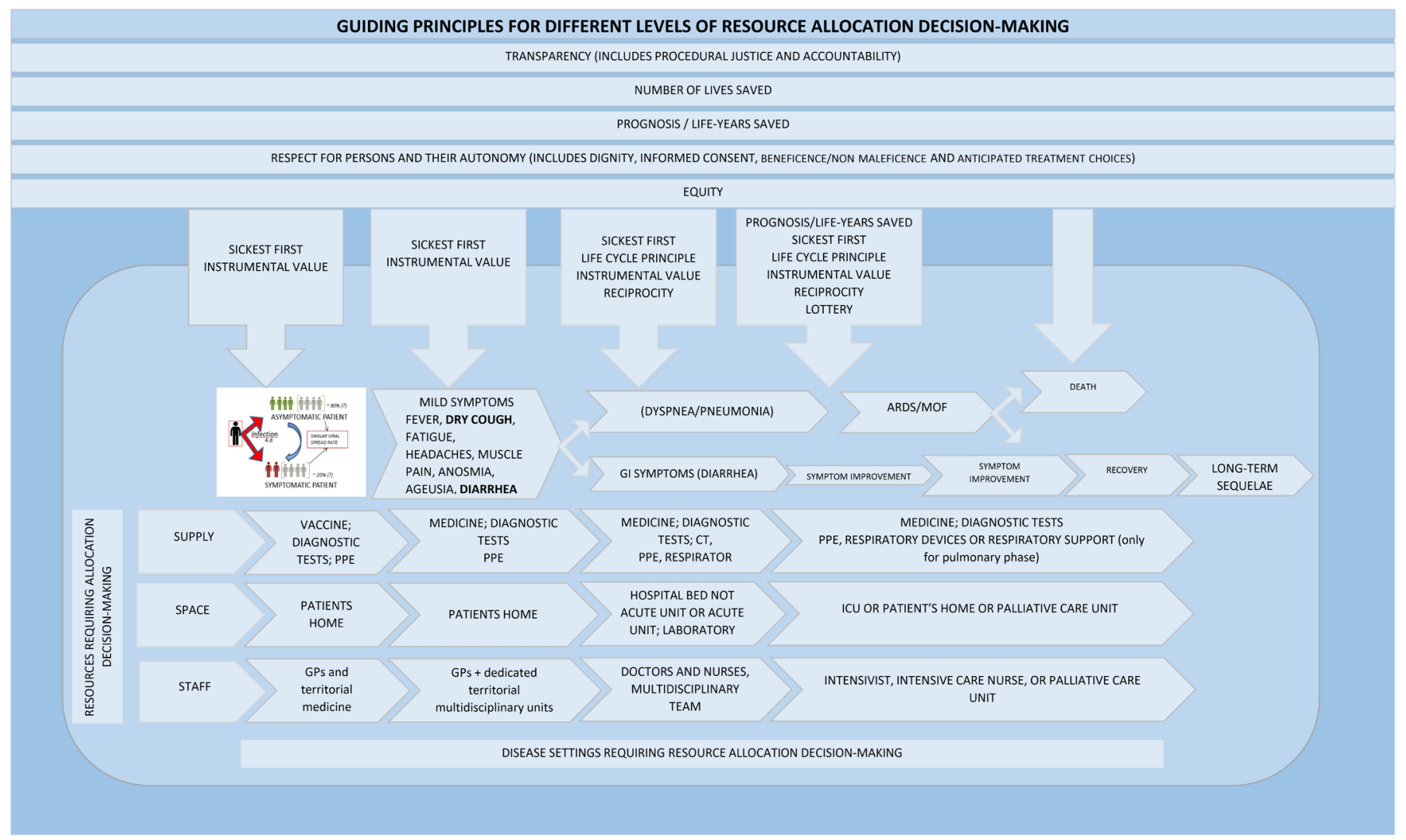

Figure 3 Application of guiding principles for resource-allocation decision-making in different disease settings. ARDS, acute respiratory distress syndrome; Gl, gastrointestinal; GPs, general practitioners; ICU, intensive care unit; MOF, multiple organ failure; PPE, personal protective equipment. 
that they require a wide legitimacy by most stakeholders before being adopted with confidence. Although being awarded for outstanding societal merits (reciprocity) can also be considered, there is a substantial risk of abuse for this principle if there is no general consensus about whose merits require such acknowledgement. Instrumental value, that is, prioritising an individual for his/her important role in the management of the health crisis, creates the so-called multiplier effect. ${ }^{252650}$ Healthcare workers are the most immediate example of this choice and again, for the panel this criterion needed to be clarified at societal level and agreed on unanimously. Lottery as a tiebreaker was judged ethically more acceptable than the first-come-first-served principle, in agreement with the majority of ethical viewpoints.

The production of a framework was outside the intended purposes of our work. Our paper highlights broader questions not only to inform the assessment of proposed triage tools by ECs, but also to set up these tools in a timely manner for future pandemic preparedness plans, which has not been done with the current pandemic. The ethical principles identified in our work are similar to those of models elaborated by working groups from other countries. However, our model, by following the identified guiding principles in order of priority (figure 3 ), enables health allocation of resources for all disease stages, whereas the majority of documents focus on the allocation of respirators and ICU beds, whose shortage is perhaps perceived as the most critical among life-saving resources. However, it should not be the foremost and only ethical concern. In fact, all healthcare resources are limited by definition, and their availability imbalance merely becomes more pronounced during a pandemic health emergency. Therefore, a broader ethical perspective on all the facets of the disease in a pandemic context is needed to minimise fatal outcomes. This entails following guiding principles to distribute PPE, vaccines, diagnostic tests and drugs according to a risk-level stratification of the population ${ }^{51}$ that prioritises those who are most likely to benefit from the resource. Embracing this approach in an ethical model is vital to avoid losing sight of what is really aggravating the scarcity of resources. In this way, we could reduce the number of individuals who develop symptomatic disease and progress to severe forms that need to be managed in a hospital setting.

In Italy, access to care is a constitutional right for all individuals regardless of race, social class and origin. ${ }^{34}$ The Italian state guarantees compliance with this law through the NHS, of which the founding principles are universality, equity ${ }^{14}$ and fairness. ${ }^{34}$ We believe that considering these guiding principles in a triage system and in a national emergency preparedness plan with specific guidelines (having binding value through the National Clinical Guidelines Clearinghouse (SNLG) and defining the standard of care by the Essential Levels of Assistance could represent a unique and secure means of their implementation. ${ }^{52} 53$
The present project could represent an important step towards harmonisation between the legitimated value of an individual's health and that of collective health in a public emergency threatening the health of society (Article 32 of the Italian Constitution), maintaining the core values of our NHS based on equality, universalism and fairness. We also believe that our work identifies a set of clear principles capable of balancing out personalistic ethical approaches traditionally followed in Italy with other pluralistic perspectives of prioritarianism, egalitarianism and utilitarianism, typical of other societies but essential in contemporary pluralistic ethical communities.

\section{LIMITATIONS}

Of note, our choices may have been partially influenced by the laws of our country and by the Italian NHS, which means that the application of the proposed model in other countries could require some specific adjustments. These principles have not been field tested, validated by other ECs, or associated with any triage tool and put into practice. The principles we prioritised reflect the viewpoint of a single, although large, EC and do not encompass the beliefs and opinions of patients and other stakeholders, nor do they derive from a participative process possessing the necessary openness and shared values needed for a communitywide, or even national acceptance of them, as done elsewhere. ${ }^{3742}$ Our selected principles are not intended to substitute a triage tool nor can they be used as a typical framework, although the ranking suggests the possibility of a sequential, reasonable use of them. Rather, our proposed principles could facilitate ECs in the scrutiny of individual patient cases competing for scarce resources and in offering ethical advice to researchers, lawyers, patient advocacy groups, and healthcare organisations striving to select, adopt or adapt effective, equitable triage tools for pandemics and other health crises.

\section{Author affiliations}

${ }^{1}$ Istituto Scientifico Romagnolo per lo Studio e la Cura dei Tumori IRST IRCCS, Meldola, Italy

${ }^{2}$ Sant'Orsola-Malpighi Hospital, University of Bologna, Bologna, Italy

${ }^{3}$ Ethical Committee AVEC, Bologna, Italy

${ }^{4}$ Sant'Anna University Hospital of Ferrara, Ferrara, Italy

${ }^{5}$ University of Rome La Sapienza, Rome, Italy

${ }^{6}$ Emergency and Trauma Surgery, Maggiore Hospital, Parma, Italy

${ }^{7}$ AUSL IRCCS, Reggio Emilia, Italy

${ }^{8}$ Higher Institute of Health, Rome, Italy

Acknowledgements The authors would like to thank Professor Paola Frati and Professor Vittorio Fineschi for collaborating in the project.

Contributors Study design (Steering Committee)—AZ, GDP, D0, PDC and PI. Literature review and data collection and analysis- $A Z, G B, G D P, P D C, D 0, F B, F C$, FP, EP, FG, RM, GV, EM and PI. Manuscript drafting - AZ, GB, FB, GDP and PI. Critical revision for important intellectual content-AZ, GB, FB, GDP, DO and PI. All authors read and approved the final version of the manuscript for submission.

Funding The authors have not declared a specific grant for this research from any funding agency in the public, commercial or not-for-profit sectors. 
Competing interests None declared.

Patient consent for publication Not required.

Provenance and peer review Not commissioned; externally peer reviewed.

Data availability statement All data relevant to the study are included in the article or uploaded as supplemental information. The authors confirm that the data supporting the findings of this study are available within the article (and/or) its supplemental materials.

Supplemental material This content has been supplied by the author(s). It has not been vetted by BMJ Publishing Group Limited (BMJ) and may not have been peer-reviewed. Any opinions or recommendations discussed are solely those of the author(s) and are not endorsed by BMJ. BMJ disclaims all liability and responsibility arising from any reliance placed on the content. Where the content includes any translated material, BMJ does not warrant the accuracy and reliability of the translations (including but not limited to local regulations, clinical guidelines, terminology, drug names and drug dosages), and is not responsible for any error and/or omissions arising from translation and adaptation or otherwise.

Open access This is an open access article distributed in accordance with the Creative Commons Attribution Non Commercial (CC BY-NC 4.0) license, which permits others to distribute, remix, adapt, build upon this work non-commercially, and license their derivative works on different terms, provided the original work is properly cited, appropriate credit is given, any changes made indicated, and the use is non-commercial. See: http://creativecommons.org/licenses/by-nc/4.0/.

ORCID iD

Francesca Bravi http://orcid.org/0000-0002-9973-720X

\section{REFERENCES}

1 The Lancet Public Health. COVID-19 puts societies to the test. Lancet Public Health 2020;5:e235.

2 Armocida B, Formenti B, Ussai S, et al. The Italian health system and the COVID-19 challenge. Lancet Public Health 2020;5:e253.

3 Gagliano A, Villani PG, Co' FM, et al. COVID-19 epidemic in the middle Province of northern Italy: impact, logistics, and strategy in the first line Hospital. Disaster Med Public Health Prep 2020;14:372-6.

4 Emanuel EJ, Persad G, Upshur R, et al. Fair allocation of scarce medical resources in the time of Covid-19. N Engl J Med 2020;382:2049-55.

5 Vergano M, Bertolini G, Giannini A, et al. Clinical ethics recommendations for the allocation of intensive care treatments in exceptional, resource-limited circumstances: the Italian perspective during the COVID-19 epidemic. Crit Care 2020;24:165.

6 Antommaria AHM, Gibb TS, McGuire AL, et al. Ventilator triage policies during the COVID-19 pandemic at U.S. hospitals associated with members of the association of bioethics program directors. Ann Intern Med 2020;173:188-94.

7 Archard D, Caplan A. Is it wrong to prioritise younger patients with covid-19? BMJ 2020;369:m1509.

8 Persad G, Wertheimer A, Emanuel EJ. Principles for allocation of scarce medical interventions. Lancet 2009;373:423-31.

9 Rosenbaum L. Facing Covid-19 in Italy - Ethics, Logistics, and Therapeutics on the Epidemic's Front Line. N Engl J Med 2020;382:1873-5.

10 COVID-19 Dashboard by the center for systems science and engineering (CSSE) at Johns Hopkins University (JHU). Available: https://coronavirus.jhu.edu/map.html [Accessed 25 Jan 2021].

11 Piccinni M, Aprile A, Benciolini P, et al. [Ethical, deontologic and legal considerations about SIAARTI Document "Clinical ethics recommendations for the allocation of intensive care treatments, in exceptional, resource-limited circumstances".]. Recenti Prog Med 2020;111:212-22.

12 Comitato Nazionale per la Bioetica (CNB). Covid-19:la decisione clinicain condizionidi carenza di risorsee il criterio del"triage in emergenzapandemica"; 2020.

13 SIAARTI - SIMLA. Decisioni per le cure intensive in caso di sproporzione tra necessit assistenziali e risorse disponibili in corso di pandemia di COVID-19. Available: https://snlg.iss.it/?cat=4

14 Legge 23 dicembre 1978, n. 833 "Istituzione del servizio sanitario nazionale". Art. 1 (I principi). Available: https://www.gazzettaufficiale. it/eli/id/1978/12/28/078U0833/sg

15 Boccia S, Cascini F, McKee M, et al. How the Italian NHS is fighting against the COVID-19 emergency. Front Public Health 2020;8:167.
16 Minni A, Ralli M, Candelori F, et al. Lessons learned from COVID-19 pandemic in Italy - A commentary. Bosn J Basic Med Sci $2021 ; 21: 117-9$

17 Legge n.189, Art. 5 e 128 November 2012. Available: http://www. eurecnet.org/information/italy.html

18 Coronavirus. Prima di arrivare a un razionamento delle cure vanno verificate tutte le disponibilit assistenziali nazionali. Statement Comitato etico Aou di Padova. quotidianosanit .it, 2020. Available: http://www.quotidianosanita.it/stampa_articolo.php?articolo_id= 83219

19 Berlinger N, Wynia M, Powell T. Ethical Framework for Health Care Institutions \& Guidelines for Institutional Ethics Services Responding to the Coronavirus Pandemic. The Hastings Center, 2020. Available: https://www.thehastingscenter.org/ethicalframeworkcovid19

20 Comitato Etico AVEC. Available: https://www.aosp.bo.it/content/ comitato-etico

21 Greenhalgh T, Peacock R. Effectiveness and efficiency of search methods in systematic reviews of complex evidence: audit of primary sources. BMJ 2005;331:1064-5.

22 Millar K, Thorstensen E, Tomkins S, et al. Developing the ethical Delphi. J Agric Environ Ethics 2007;20:53-63.

23 Hasson F, Keeney S, McKenna H. Research guidelines for the Delphi survey technique. J Adv Nurs 2000;32:1008-15.

24 Rawls J. A theory of justice. Cambridge, MA: Harvard University Press, 1971.

25 Ethics Subcommittee of the Advisory Committee to the Director, Centers for Disease Control and Prevention. Ethical considerations for decision making regarding allocation of mechanical ventilators during a severe influenza pandemic or other public health emergency. Centers for Disease Control and Prevention, 2011. https://www.cdc.gov/about/advisory/pdf/VentDocument_Release. pdf

26 Daugherty Biddison EL, Faden R, Gwon HS, et al. Too many patients... a framework to guide statewide allocation of scarce mechanical ventilation during disasters. Chest 2019;155:848-54.

27 Biddison LD, Berkowitz KA, Courtney B, et al. Ethical considerations: care of the critically ill and injured during pandemics and disasters: chest consensus statement. Chest 2014;146:e145S-55.

28 Swiss Academy Of Medical Sciences. COVID-19 pandemic: triage for intensive-care treatment under resource scarcity. Swiss Med Wkly 2020;150:w20229.

29 Conway CA. Texas ethics group provides recommendations on allocation of health care services during an influenza pandemic, 2010. Available: http://www.bioethics.net/wp-content/uploads/2020/ 03/Texas-Pandemic.pdf?x26147

30 Smith M, Upshur R. Pandemic disease, public health, and ethics. In: The Oxford Handbook of public health ethics. Oxford University Press, 2019.

31 O'Laughlin DT, Hick JL. Ethical issues in resource triage. Respir Care 2008;53:190-200.

32 Emanuel EJ. Justice and managed care. four principles for the just allocation of health care resources. Hastings Cent Rep 2000;30:8-16.

33 Post-Covid bioethics. Available: https://www.thehastingscenter.org/ post-covid-bioethics

34 Art. 2, 13 and 32 of the Italian constitution. Available: https://www. senato.it/documenti/repository/istituzione/costituzione_inglese.pdf

35 Legge 22 Dicember 2017, n. 219. Available: https://www. gazzettaufficiale.it/eli/id/2018/1/16/18G00006/sg

36 Daniels N. Accountability for Reasonableness. BMJ 2000;321:1300-1.

37 Wilkinson D, Zohny H, Kappes A, et al. Which factors should be included in triage? An online survey of the attitudes of the UK general public to pandemic triage dilemmas. BMJ Open 2020;10:e045593.

38 Lamblin A, de Montgolfier S. COVID-19 and ethical considerations: valuable decision-making tools from the leading medical societies in France. Anaesth Crit Care Pain Med 2020;39:365-6.

39 Savulescu J, Cameron J, Wilkinson D. Equality or utility? Ethics and law of rationing ventilators. $B r J$ Anaesth 2020;125:10-15.

40 Rubio O, Estella A, Cabre L, et al. [Ethical recommendations for a difficult decision-making in intensive care units due to the exceptional situation of crisis by the COVID-19 pandemia: a rapid review \& consensus of experts]. Med Intensiva 2020;44:439-45.

41 Dos Santos MJ, Martins MS, Santana FLP, et al. COVID-19: instruments for the allocation of mechanical ventilators-a narrative review. Crit Care 2020;24:582.

42 Buckwalter W, Peterson A. Public attitudes toward allocating scarce resources in the COVID-19 pandemic. PLOS One 2020;15:e0240651.

43 Cleveland Manchanda E, Couillard C, Sivashanker K. Inequity in crisis standards of care. N Engl J Med 2020;383:e16.

44 Persad G, Wassermann D. Diversity and solidarity in response to COVID-19, 2020. The Hastings Center. Available: https://www. 
thehastingscenter.org/diversity-and-solidarity-in-response-to-covid19

45 White DB, Lo B. A framework for rationing ventilators and critical care beds during the COVID-19 pandemic. JAMA 2020;323:1773-4.

46 Lopez L, Hart LH, Katz MH. Racial and ethnic health disparities related to COVID-19. JAMA 2021;325:719-20.

47 Harris J. The value of life: an introduction to medical ethics. New York: Routledge, 1985: 93.

48 Lesser H. Ageism. In: Chadwick R, ed. Encyclopedia of applied ethics. 93. 1st edn. London: Academic Press, 1998.

49 Davies B. Fair Innings and Time-Relative claims. Bioethics 2016;30:462-8.
50 Bledsoe TA, Jokela JA, Deep NN, et al. Universal do-not-resuscitate orders, social worth, and life-years: opposing discriminatory approaches to the allocation of resources during the COVID-19 pandemic and other health system catastrophes. Ann Intern Med 2020;173:230-2.

51 Boreskie KF, Boreskie PE, Melady D. Age is just a number - and so is frailty: Strategies to inform resource allocation during the COVID-19 pandemic. CJEM 2020;22:411-3.

52 Legge n.24, 8 marzo, 2017. Available: https://www.gazzettaufficiale. it/eli/id/2017/03/17/17G00041/sg

53 Gazzetta Ufficiale (Supplemento ordinario n.15) 18 marzo 2017 Decreto del Presidente del Consiglio dei Ministri (DPCM) del 12 gennaio 2017 con i nuovi Livelli essenziali di assistenza. 